\title{
A Feline Case of Hepatic Neuroendocrine Carcinoma with Gastrin Immunoreactivity
}

\author{
Chiaki KITA ${ }^{1) *}$, Tetsushi YAMAGAMI ${ }^{1)}$, Shigemi KINOUCHI ${ }^{1}$, Masayuki NAKANO ${ }^{1)}$, Nao NAGATA ${ }^{2)}$, \\ Hitomi SUZUKI ${ }^{2)}$, Yuzo OHTAKE ${ }^{2)}$, Takuma MIYOSHI ${ }^{2)}$, Mitsuhiro IRIE ${ }^{2)}$ and Kazuyuki UCHIDA ${ }^{3)}$ \\ ${ }^{1)}$ Shikoku Cytopathological Laboratory, 712 Rokujyo, Takamatsu, Kagawa 761-0303, Japan \\ ${ }^{2)}$ Shikoku Veterinary Medical Center, 3308-5 Ikenobe, Miki, Kita-gun, Kagawa 761-0701, Japan \\ ${ }^{3)}$ Department of Veterinary Pathology, Graduate School of Agricultural and Life Science, The University of Tokyo, 1-1-1 Yayoi, Bunkyo-ku, \\ Tokyo 113-8657, Japan
}

(Received 19 November 2013/Accepted 16 January 2014/Published online in J-STAGE 31 January 2014)

ABSTRACT. A 5-year-old castrated Japanese domestic cat was presented with persistent vomiting. Ultrasound examinations revealed many masses only in the liver, and the fine needle aspiration was performed. Cytologically, polygonal or oval shaped tumor cells forming rosette and cord-like patterns were demonstrated, and then, the hepatic lesions were diagnosed as neuroendocrine carcinoma tentatively. The cat died one month after admission and was necropsied. Histopathologically, the tumor cells of the hepatic mass were arranged in typical rosette and cord-like structures. They were considerably uniform in size with hyperchromatic round nuclei and eosinophilic cytoplasm. Most of tumor cells were immunopositive for chromogranin A, and some were positive for gastrin. The findings indicate the possibility that the present case was a gastrin-producing neuroendocrine carcinoma.

KEY WORDS: feline, gastrin, liver, neuroendocrine carcinoma.

doi: 10.1292/jvms.13-0581; J. Vet. Med. Sci. 76(6): 887-890, 2014

Neuroendocrine carcinomas (carcinoids) are malignant tumors arising from neuroendocrine cells. These tumor cells are known to produce biogenic amines and peptides [3]. Therefore, some neuroendocrine carcinomas produce pathological condition with endocrine malfunctions. In dogs and cats, the case reports concerning these tumors have been limited. Previously, neuroendocrine carcinomas were found in several organs including the intestines $[6,10,13]$, skin $[4,7]$, nasal cavity [11], bile duct [5], gallbladder [5] and liver [2, $5,8,9]$. Moreover, hepatic neuroendocrine carcinomas have been very rare in the cats. To the authors' knowledge, only 4 case reports described primary hepatic neuroendocrine carcinomas in cats $[1,2,5,9]$. In 1992, the first case study in a cat was recorded among 47 feline neoplasms of hepatic biliary system at observation period from 1980 to 1989 [5].

The present paper describes clinical and pathological features of a feline hepatic neuroendocrine carcinoma with gastrin immunoreactivity.

A 5-year-old castrated Japanese domestic mongrel cat was presented with persistent vomiting and anorexia for three months and was referred to Shikoku Veterinary Medical Center (SVMC). In the complete blood count, the platelet count was slightly decreased $\left(140 \times 10^{3} / \mu l\right.$;reference range: $\left.300-800 \times 10^{3} / \mu l\right)$. The other values were within the normal range. The biochemical examination using a plasma constituent revealed increases in alanine aminotransferase (ALT,

*Correspondence to: Kita, C., Shikoku Cytopathological Laboratory, 712 Rokujyo, Takamatsu, Kagawa 761-0303, Japan. e-mail: kitachiaki0000@gmail.com

(C2014 The Japanese Society of Veterinary Science

This is an open-access article distributed under the terms of the Creative Commons Attribution Non-Commercial No Derivatives (by-nc-nd) License $<$ http://creativecommons.org/licenses/by-nc-nd/3.0/>.
$279 \mathrm{U} / l$; reference range: $22-84 \mathrm{U} / l)$, glutamic oxaloacetic transaminase (GOT, $151 \mathrm{U} / l$; reference range: $26-43 \mathrm{U} / l$ ) and glucose $(175 \mathrm{mg} / \mathrm{d} l$; reference range: $50-150 \mathrm{mg} / \mathrm{d} l)$, and a decrease in potassium $(3.2 \mathrm{mEq} / l$; reference range: $4.0-4.5$ $\mathrm{mEq} / l$ ). The cat tested positive for feline immuno-deficiency virus (FIV) and negative for feline leukemia virus (FeLV). Endoscopic examinations revealed the gastric ulcer. Ultrasound examination revealed many hyperechoic mass lesions in the liver. The range of the diameters of mass was from 1-3 cm (Fig. 1). The fine needle aspiration cytology was performed at the same time and then stained with WrightGiemsa. There were many polygonal or oval shaped tumor cells with few red blood cells in the specimens. Cytologically, these tumor cells tend to be attached, forming rosette and cord-like patterns. The tumor cells were similar and of moderate size with hyperchromatic round nuclei and scant cytoplasm (Fig. 2). Based on these cytological findings, we initially diagnosed as a hepatic neuroendocrine carcinoma. Since surgical procedure is difficult and prospective prognosis of the tumor is poor, the cat received the supportive care for vomiting.

The cat died one month after admission, and necropsy was performed on the same day with informed consent. There were grossly white or red multiple nodules in all lobes of the liver. The nodules were solid and $1-3 \mathrm{~cm}$ in diameter (Fig. 3 ). Extrahepatic bile ducts and gallbladder were not affected. The metastatic masses were not found in the other visceral organs. The mild multiple gastric erosion with hemorrhage was observed.

Tissue samples from all visceral organs were fixed in 10\% neutral formalin, dehydrated in a graded series of ethanol, embedded in paraffin and stained with hematoxylin and eosin (HE). Histopathologically, the hepatic nodules consisted of solid proliferation of the tumor cells with multiple necro- 


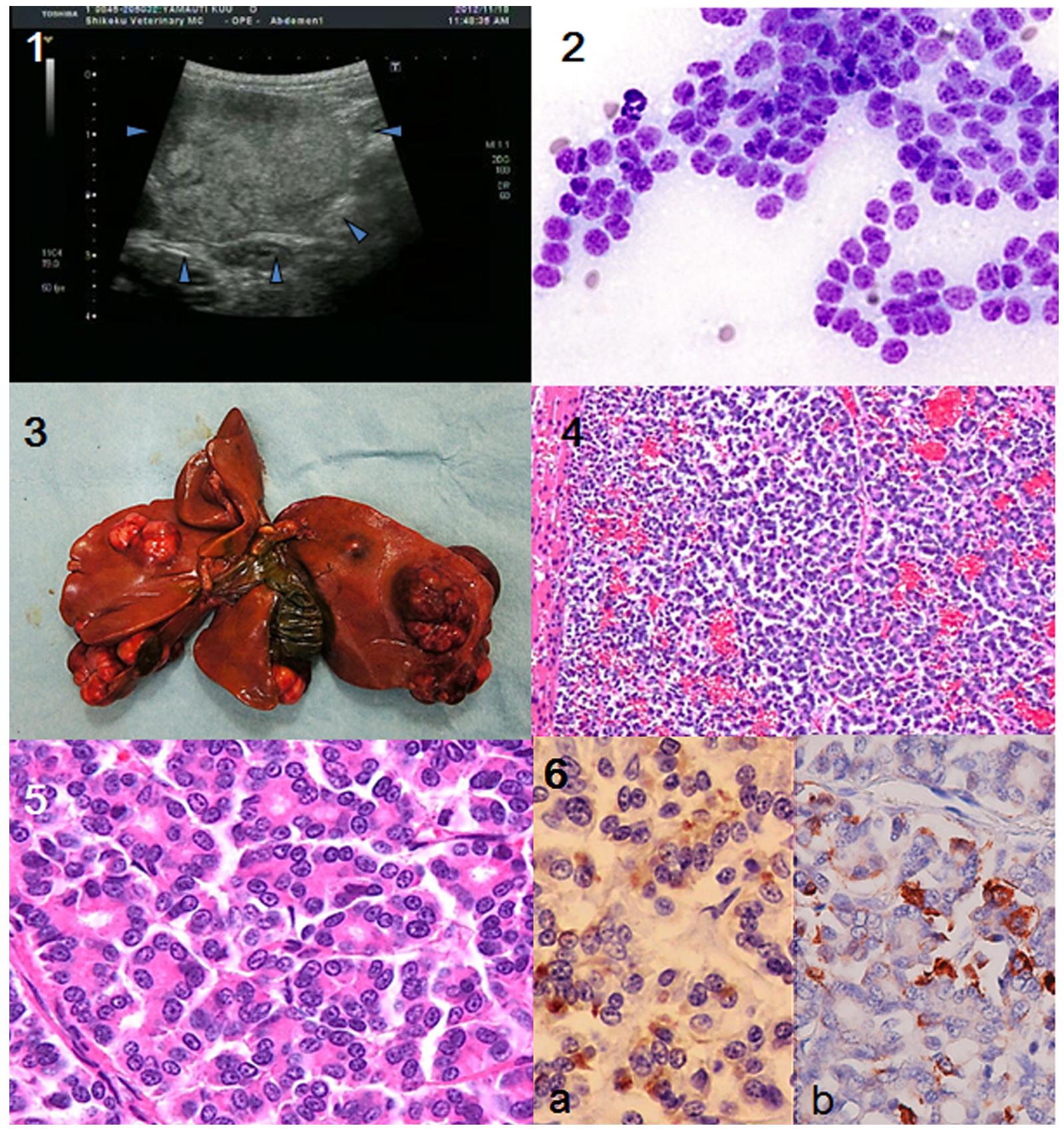

Fig. 1. Ultrasound examination of nodular changes in the liver. The arrows show hyperechoic nodules with irregular border.

Fig. 2. Cytologically, the tumor cells tend to be attached, forming rosette- or cord-like patterns. Wright-Giemsa $(\times 400)$.

Fig. 3. Gross appearence of the liver. The white or red multiple nodules are scattered in all lobes of the liver.

Fig. 4. The hepatic nodules consist of solid proliferation of the tumor cells, and the neoplastic foci are loosely demarcated from the intact hepatic tissues. HE $(\times 100)$.

Fig. 5. The tumor cells are arranged in rosette, cord-like and solid structures in the liver. They are separated by fine fibrovascular stroma. HE $(\times 400)$.

Fig. 6. Immunoreactivity of the tumor cells for chromogranin A (a) and gastrin (b). Most of tumor cells are immunopositive for chromogranin A, and some are immunopositive for gastrin. Immunostaining with hematoxylin counter stain $(\times 400)$. 
sis, and the neoplastic foci were loosely demarcated from the intact hepatic tissues (Fig. 4). The tumor cells were arranged in rosette, cord-like and solid structures, and they were separated by fine fibrovascular stroma (Fig. 5). The tumor cells were considerably uniform in size with hyperchromatic round to oval nuclei and eosinophilic cytoplasm with many granules. The nucleus/cytoplasm ratio was high. The mitotic cells were found zero to 2 per high-power field. In the stomach, the erosion was recognized. The lack of mucosal epithelium and glandular epithelium was observed there. Inflammatory cells including macrophages and lymphocytes infiltrated the remained lamina propria. No neoplastic lesions were found in other organs examined. In particular, no lesions were recognized in the gastrointestinal tracts and pancreas.

Immunohistochemical stains were performed using the Envision polymer reagent (Dako-Japan, Kyoto, Japan). Primary monoclonal antibodies were against chromogranin A (Dako-Japan), hepatocyte (Dako-Japan), somatostatin (Dako-Japan), cytokeratin AE1/AE3 (Dako-Japan) and gastrin (prediluted, Dako) antigens. The antigen retrieval pretreatments and dilution of the antibodies were based on the manufacturer's recommendations. Most of tumor cells were immunopositive for chromogranin A (Fig. 6a). The tumor cells were also immunopositive for gastrin (Fig. 6b). The percentage of positive cells for gastrin was approximately $9.7 \%$ of the tumor cells when positive cells were counted in randomly selected-10 fields under the $40 \times$ objective lens. There was no tendency in the distribution of the positivity for gastrin. The tumor cells were negative for hepatocyte, somatostatin and cytokeratin AE1/AE3. Based on these findings, we definitively diagnosed as a hepatic neuroendocrine carcinoma. In addition, the immunohistochemical results indicate the possibility that the present case has the nature of a gastrin-producing tumor.

In cytological diagnosis, it would be difficult to distinguish neuroendocrine carcinoma from cholangiocarcinoma due to their similar tubular or rosette-like structures. However, vesicles in nuclei of cells and presence of the mesenchymal cells inducing severe fibrosis might be helpful for diagnosis of cholangiocarcinoma. Histopathologically, neuroendocrine carcinoma can be also confused with cholangiocarcinoma. However, it is worth remembering that neuroendocrine carcinoma cells do not contain mucin. In addition, variable amount of fine fibrovascular stroma with an abundant vascular supply is characteristic in neuroendocrine carcinoma. Morphologically, the cells tend to be oriented toward the basement membrane and vary from polyhedral elongate columnar shape. Moreover, an immunohistochemical study can be very useful approach. Immunohistochemical detection of neuron-specific enolase or specific neurosecretary products, such as chromogranin A, assists in making a diagnosis [3]. From comprehensive evaluation with histopathological and immunohistochemical examinations, we could achieve definitive diagnosis in this case.

Gastrointestinal and pancreatic neuroendocrine cells belong to the diffuse neuroendocrine cell complex, which secretes amines and peptides for the purpose of maintaining homeostasis of the body. There are specific tumors arising from neuroendocrine cells known to produce amines and peptides [3]. Therefore, some neuroendocrine carcinomas have endocrine functions. Zollinger-Ellison syndrome in humans and domestic animals is caused by a functional tumor of gastrin-producing cells. This results in a marked increase in serum gastrin concentration that serves as a potent stimulus for gastric acid secretion. Then, secondary severe gastrointestinal ulcers will be produced with the gastric acid hypersecretion. The first case resembling Zollinger-Ellison syndrome in a dog was described in 1976. To date, one feline and seven canine cases have been described [12]. We supposed that the present neuroendocrine carcinoma was the functional tumor and could be called as "gastrin-producing carcinoma" based on its gastrin-positive immunohistochemical results and clinical features of the present case. Although we could not evaluate a serum gastrin level, it will be speculated high serum gastrin level in the survival time. In hepatic neuroendocrine carcinoma, intrahepatic, lymphogenous and transcoelomic metastases are frequent [3]. In spite of no metastasis to any other organs in this case, the cat died soon after admission. Thus, we considered that the cat could not gain enough nutrients with chronic vomiting by gastrointestinal disorder due to gastrin hypersecretion.

As far as we know, there were no reports concerning on hepatic gastrin-producing tumor in a cat. Even though it is rare to encounter neuroendocrine carcinoma (carcinoid), the tentative diagnosis can be made by clinical symptom and cytology in animal's survival time. For the definitive diagnosis of this tumor, detailed histological and immunohistochemical examinations are required.

ACKNOWLEDGMENT. We thank Mr. Masakazu Ishikawa for his editorial assistance.

\section{REFERENCES}

1. Asakawa, M. G., Cullen, J. M. and Linder, K. E. 2013. Necrolytic migratory erythema associated with a glucagon-producing primary hepatic neuroendocrine carcinoma in a cat. Vet. Dermatol. 24: 466-469. [Medline] [CrossRef]

2. Ferreira-Neves, P., Lezmi, S., Lejeune, T., Rakotovao, F., Dally, C., Fontaine, J. J., Bernex, F. and Cordonnier, N. 2008. Immunohistochemical characterization of a hepatic neuroendocrine carcinoma in a cat. J. Vet. Diagn. Invest. 20: 110-114. [Medline] [CrossRef]

3. Head, K. H., Cullen, J. M., Dobielzig, R. R., Else, R. W., Misdorp, W., Patnaik, A. K., Tateyama, S. and van der Gaag, I. 2003. World Health Organization. Histological Classification of Tumors of the Alimentary System of Domestic Animals. AFIP, Washington, D.C., U.S.A.

4. Ozaki, K. and Narama, I. 2009. Merkel cell carcinoma in a cat. J. Vet. Med. Sci. 71: 1093-1096. [Medline] [CrossRef]

5. Patnaik, A. K. 1992. A morphologic and immunocytochemical study of hepatic neoplasms in cats. Vet. Pathol. 29: 405-415. [Medline] [CrossRef]

6. Patnaik, A. K., Hurvitz, A. I. and Johnson, G. F. 1980. Canine intestinal adenocarcinoma and carcinoid. Vet. Pathol. 17: 149-163. [Medline]

7. Patnaik, A. K., Post, G. S. and Erlandson, R. A. 2001. Clinico- 
pathologic and electron microscopic study of cutaneous neuroendocrine (Merkel cell) carcinoma in a cat with comparisons to human and canine tumors. Vet. Pathol. 38: 553-556. [Medline] [CrossRef]

8. Patnaik, A. K., Newman, S. J., Scase, T., Erlandson, R. A., Antonescu, C., Craft, D. and Bergman, P. J. 2005. Canine hepatic neuroendocrine carcinoma: an immunohistochemical and electron microscopic study. Vet. Pathol. 42: 140-146. [Medline] [CrossRef]

9. Patnaik, A. K., Lieberman, P. H., Erlandson, R. A. and Antonescu, C. 2005. Hepatobiliary neuroendocrine carcinoma in cats: a clinicopathologic, immunohistochemical, and ultrastructural study of 17 cases. Vet. Pathol. 42: 331-337. [Medline] [CrossRef]
10. Sako, T., Uchida, E., Okamoto, M., Yamamoto, E., Kagawa, Y., Yoshino, T., Hirayama, K. and Taniyama, H. 2003. Immunohistochemical evaluation of a malignant intestinal carcinoid in a dog. Vet. Pathol. 40: 212-215. [Medline] [CrossRef]

11. Sako, T., Shimoyama, Y., Akihara, Y., Ohmach, T., Yamashita, K., Kadosawa, T., Nakade, T., Uchida, E., Okamoto, M., Hirayama, K. and Taniyama, H. 2005. Neuroendocrine carcinoma in the nasal cavity of ten dogs. J. Comp. Pathol. 133: 155-163. [Medline] [CrossRef]

12. Shaw, D. H. 1988. Gastrinoma (Zollinger-Ellison Syndrome) in the Dog and Cat. Can. Vet. J. 29: 448-452. [Medline]

13. Sykes, G. P. and Cooper, B. J. 1982. Canine intestinal carcinoids. Vet. Pathol. 19: 120-131. [Medline] [CrossRef] 